\title{
Clinical approach for the classification of congenital uterine malformations
}

\author{
Grigoris F. Grimbizis • Rudi Campo • \\ On behalf of the Scientific Committee of the Congenital \\ Uterine Malformations (CONUTA) common ESHRE/ \\ ESGE working group: Stephan Gordts, Sara Brucker, \\ Marco Gergolet, Vasilios Tanos, T.-C. Li, Carlo De \\ Angelis, Attilio Di Spiezio Sardo
}

Received: 3 December 2011 / Accepted: 28 December 2011 /Published online: 10 March 2012

(C) The Author(s) 2012. This article is published with open access at Springerlink.com

\begin{abstract}
A more objective, accurate and non-invasive estimation of uterine morphology is nowadays feasible based on the use of modern imaging techniques. The validity of the current classification systems in effective categorization of the female genital malformations has been already challenged. A new clinical approach for the classification of uterine anomalies is proposed. Deviation from normal uterine anatomy is the basic characteristic used in analogy to the American Fertility Society classification. The embryological origin of the anomalies is used as a secondary parameter. Uterine anomalies are classified into the following classes: 0 , normal uterus; I, dysmorphic uterus; II, septate uterus (absorption defect); III, dysfused uterus (fusion defect); IV, unilateral formed uterus (formation defect); V, aplastic or dysplastic uterus (formation defect); VI, for still unclassified cases. A subdivision of these main classes to further anatomical varieties with clinical significance is also presented. The new proposal has been designed taking into account the experience gained from the use of the currently available classification systems and intending to be as simple as possible, clear enough and accurate as well as open for
\end{abstract}

G. F. Grimbizis · R. Campo

European Academy for Gynecological Surgery,

Scientific project on Female Genital Tract Congenital Anomalies,

Diestsevest 43/0001,

3000 Leuven, Belgium

G. F. Grimbizis $(\bowtie)$

First Department of Obstetrics and Gynecology,

Aristotle University of Thessaloniki,

Tsimiski 51 Street,

54623 Thessaloniki, Greece

e-mail: grigoris.grimbizis@gmail.com

G. F. Grimbizis

e-mail: grimbi@med.auth.gr further development. This proposal could be used as a starting point for a working group of experts in the field.

Keywords Uterine anomalies · Mullerian anomalies . Classification $\cdot$ Septate uterus

\section{Introduction}

Female genital tract anomalies are common deviations from normal anatomy with an estimated prevalence of $4-7 \%$ in the general population and even higher in selected populations such as recurrent aborters [1-3]. Their occurrence could be associated with a variety of clinical presentations ranging between life threatening complications, severe health problems in the adolescence, reproductive problems although in most of them they are asymptomatic [1, 4-16].

Due to their high prevalence and possible impact on the reproductive health of women, congenital uterine malformations of the female genital tract are a challenge for the therapeutic decision-making process. An efficient planning of the therapeutic strategy is based on their effective diagnosis and clear categorization, in view also of the numerous treatment options available for their management. The need for a reliable classification system is more than obvious [4].

The first attempt to classify female congenital anomalies goes back to the beginning of the 19th century; Strassmann described septate and bicornuate uterus and some subgroups of the disorders in 1907. However, the first classification system for categorization of congenital uterine malformations was that of the American Fertility Society (AFS) published in 1988, mostly based on the previous work of Buttram and Gibbons [17, 18]. Almost 15 years later, Acien et al. [19] proposed another option for the classification of 
congenital female malformations using the embryological origin as the basis of the system. A newer version of this classification has been published recently [20]. Furthermore, Oppelt et al. [21] published a very detailed classification system based on the Tumor Nodes Metastases (TNM) principle in oncology and known as vagina, cervix, uterus, adnexae and associated malformations (VCUAM) classification system. It is also interesting that, apart from these alternatives for the classification of the female genital malformations in general, some other subdivisions for certain categories of anomalies have been published [22-27].

Although the AFS classification received wide acceptance and it is still the most broadly used system, it is associated with various limitations in effective categorization of the anomalies. It is also interesting that until now none of the other available options was able to effectively replace the AFS system [4].

The European Academy for Gynaecological Surgery (EAGS), recognizing the need for an evidence-based updated classification of female genital tract malformations, has established a scientific project on that issue. As the first step of this project, a systematic re-evaluation of the current proposals has been done and, based on their criticism, the characteristics of the new classification system have been clarified [4]. The second and final step of the EAGS scientific project was to prepare a proposal for the new updated clinical classification of uterine anomalies to be used as the scientific background for a working group of experts in the field. This proposal, after extensive discussion, has been also adopted as the scientific basis for the development of a new classification system by the common working group meanwhile established by the European Society of Human Reproduction and Embryology (ESHRE) and European Society for Gynaecological Endoscopy (ESGE) under the working name CONUTA (CONgenital UTerine Anomalies). The development of the new system will run using the DELPHI procedure of consensus.

The updated new proposal for the classification of uterine congenital anomalies is designed having mainly clinical orientation and based on a critical review of the available data on female genital tract malformations with their extensive interpretation. Further subdivisions based on the cervical and vaginal anatomy, incorporating all the possible co-existent anomalies and their combinations, are feasible but they are not in the goals of the present article. Thus, the system is open for further development in order to be more comprehensive.

\section{Design of the new system: main concepts}

The first and fundamental starting point in the design of the new proposal for a classification system was, initially, to select the basic characteristic for patients' grouping. Thus, anatomy of the female genital tract is thought to be the most appropriate basic characteristic for the systematic categorization of the women with congenital anomalies in a new classification system for the following reasons: (1) by definition, congenital anomalies of the female genital tract are miscellaneous deviations from normal anatomy [4], (2) clinical presentation and prognosis of the patients seems to be correlated with the type and the degree of anatomical deformity of the genital tract [2, 4-16, 28-32] (3) anatomy is the basis of the AFS classification system which is successfully adopted as the main classification system for more than two decades, indicating the real value of the anatomy in that respect $[4,17]$.

The second point in the design of the new proposal is to decide if there is a "key" organ in the anatomy of the female genital tract that could be used by priority to build up the main groups of the system. Thus, uterine anatomy was selected as the key characteristic for the main groups of the system for the following reasons: (1) frequency should be taken into account in the design of the system and the vast majority of the congenital malformations of the female genital tract are, no doubt, uterine ones $[1-3,33,34]$; (2) uterine anatomy is the basis in the design of the AFS classification system and it is thought to be one of the advantages of this system explaining, also, its wide acceptability; the adoption of the same characteristic by the new system will facilitate the clinicians to smoothly move from the old to the new system $[4,17]$.

Although uterine anatomy has been selected as the main characteristic in the design of the new classification system another crucial point was to choose if there is another supplementary characteristic that could be used in the design of the patients' grouping. Uterine congenital malformations are the result of very discrete disturbances in the embryologic development of the Müllerian (or para-mesonephric) ducts during fetal life thus explaining their pathogenesis [9, 35, 36]. Due to its independent importance, embryological origin of uterine anomalies has been adopted as a secondary basic characteristic in the design of the main groups of the new proposal. The incorporation of embryology as an additional basic characteristic helps to create (1) more uniform classes avoiding transitional unclassified or cases with unclear classification and, (2) more "clear" classes since each class has a common pathogenesis due to the fact that, usually, very discrete embryological disturbances underlie to each patients' group.

\section{Proposed uterine classification: key concepts}

The new proposed system has the following general characteristics: (a) the main classes are based on the uterine anatomy and embryology and express main anatomical variations of uterine anatomy coming from the same embryological origin; (b) the main sub-classes are further anatomical variations of the main classes expressing different degrees of uterine deformity. 
In general, two options are available for the classification of uterine anomalies: the first is to go from the normal uterus (as class 0 or I) to the more deformed types, e.g., uterine aplasia/ dysplasia (as class VI), and the other one is to go from the more severe forms (uterine aplasia/dysplasia as class I) to the normal uterus (as class VI), an approach followed in the ASRM classification system. In the new system, the first way of classification is adopted, with normal uterus being class 0, since: (1) it seems to be more reasonable to start from less affected to more affected cases and (2) the scientific society is familiar mainly with this practice followed also in the categorization of cancer, endometriosis, etc.

As already mentioned, each main class is further divided into sub-classes. The mode of classification adopted in subclasses is to go from the less severe forms to the more severe ones and the numbers are the alphabet of the Latin language $(a, b, c)$. It should be noted that, for the needs of simplicity, an extremely detailed further sub-classification is avoided in order to stay away from too many sub-divisions, which seems not to be very functional. Thus, sub-classes include variations of the same embryological anatomical entity with clinical different significance.

The main classes and the subclasses of the new system are presented in Table 1 and are as follows (Fig. 1):

Class 0 - normal uterus

Class I - dysmorphic uterus; Ia T-shaped uterus and $I b$ uterus infantilis

Class II - septate uterus; IIa partial septate uterus and IIb complete septate uterus

Class III - dysfused uterus, IIIa partial disfused uterus and IIIb complete dysfused uterus

Class IV - unilaterally formed uterus (formerly unicornuate uterus); $\mathrm{IVa}$ horn with cavity (communicating or not), $I \mathrm{Vb}$ horn without cavity or aplasia
Class V - aplastic/dysplastic uterus; Va bilateral or unilateral horn with cavity and $I b$ bilateral or unilateral horn without cavity or aplasia of both parts

Class VI - for still unclassified cases

Definitions

(a) Class 0 incorporates all cases with normal uterus giving the opportunity to classify congenital malformations of the other parts of female genital tract apart from the uterus in the fully developed classification system $[25,26,37-53]$.

(b) Class $I$ incorporates all cases having a uterus with normal outline but with an abnormal lateral wall's shape of the uterine cavity. The Greek term "dysmorphia" is used to describe the cavity with this abnormal morphology. Class I is further subdivided into two categories: (a) T-shaped uterus characterized by a correlation of $2 / 3$ uterine corpus and $1 / 3$ cervix and (b) uterus infantilis characterized by an inverse correlation of $1 / 3$ uterine body and $2 / 3$ cervix. It should be noted, however, that both subclasses have almost the same appearance in hysterosalpingography (HSG) and magnetic resonance imaging (MRI) and differential diagnosis could be done mainly by hysteroscopy and biopsy of the endocervix and endometrium.

(c) Class II incorporates all cases with normal fusion and abnormal absorption of the midline septum. Thus, septate uterus is characterized as any uterus with a normal outline and with an inner indentation at the midline level (septum) that divides the cavity. A septum is defined any indentation at the midline level exceeding at least by $50 \%$ (half) the uterine wall thickness and reaching up to the full division of the cavity and/or the

Table 1 Classification of uterine anomalies

\begin{tabular}{|c|c|c|}
\hline Main class & Uterine anomaly & Main sub-classes \\
\hline Class 0 & Normal uterus & \\
\hline Class I & Dysmorphic uterus & $\begin{array}{l}\text { a. T-shaped } \\
\text { b. Infantilis }\end{array}$ \\
\hline Class II & Septate uterus & $\begin{array}{l}\text { a. Partial } \\
\text { b. Complete }\end{array}$ \\
\hline Class III & Dysfused uterus & $\begin{array}{l}\text { a. Partial } \\
\text { b. Complete }\end{array}$ \\
\hline Class IV & Unilateral formed uterus & $\begin{array}{l}\text { a. Rudimentary horn with cavity (Communicating or not) } \\
\text { b. Rudimentary horn without cavity/Aplasia (no horn) }\end{array}$ \\
\hline Class V & Aplastic/dysplastic uterus & $\begin{array}{l}\text { a. Rudimendary horn with cavity (bi- or unilateral) } \\
\text { b. Rudimentary horn without cavity (bi- or unilateral)/Aplasia }\end{array}$ \\
\hline Class VI & Unclassified malformations & \\
\hline
\end{tabular}




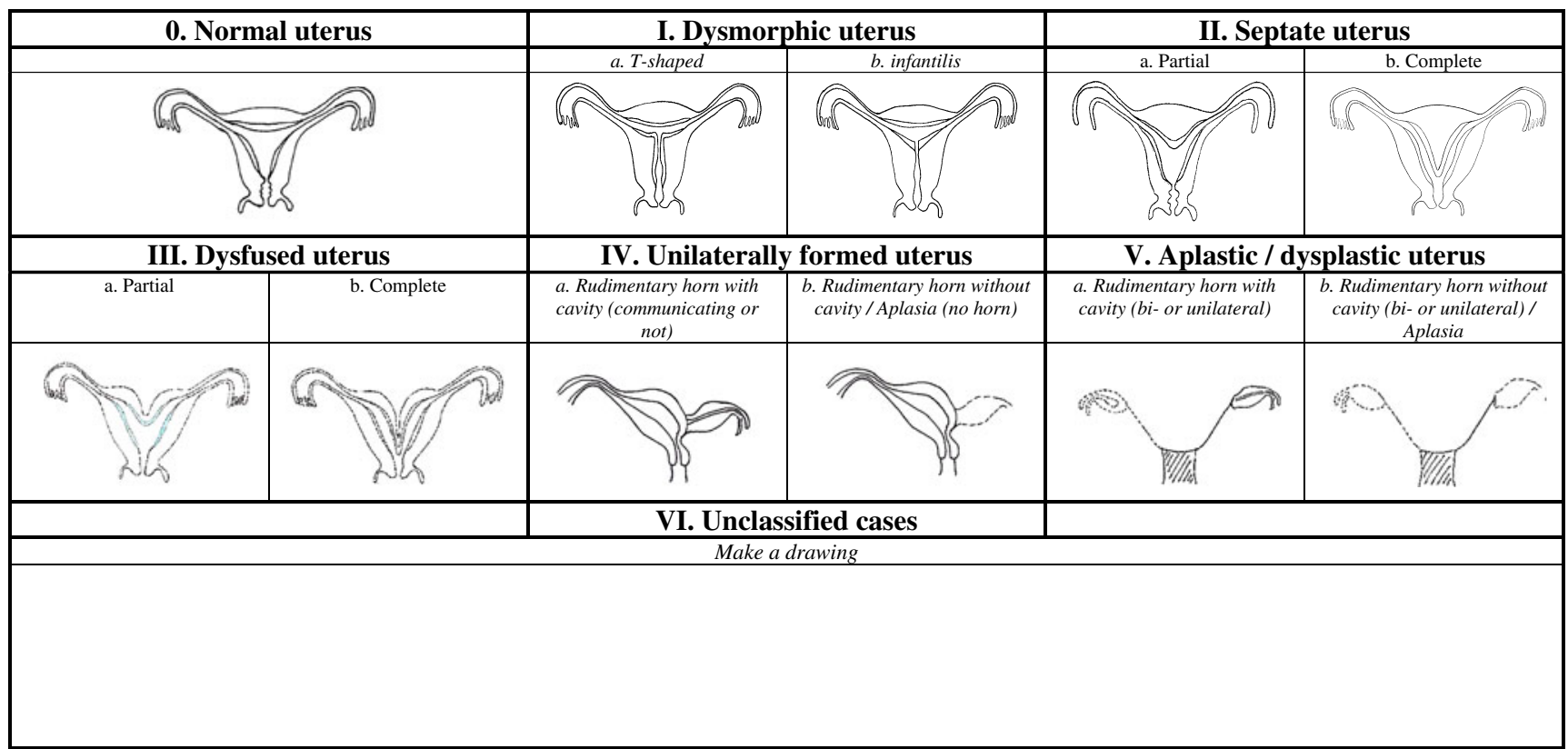

Fig. 1 Schematic representation of uterine anomalies' classification

cervix and/or the vagina into two distinct parts. It should be noted that in definitions, the use of absolute numbers (e.g., indentation of $5 \mathrm{~mm}$ ) is avoided since the "normal" uterine dimensions as well as uterine wall thickness are not known and they could be different from one patient to another. Thus, it seems more justified to define uterine deformity as proportions of each patient's uterine anatomical condition [54].

Class II is further divided into two sub-classes according to the degree of the uterine cavity deformity (uterine corpus, including or not the cervix): (a) partial septate uterus is characterized by the presence of any septum partially dividing the uterine cavity above the level of the internal cervical oss; (b) complete septate uterus is characterized by the presence of a septum fully dividing the uterine cavity up to the level of the internal cervical oss. Cases with cervical (e.g., bicervical septate uterus) and/or vaginal defects [55-61] can be further sub-classified with the addition of cervical and/or vaginal congenital anomalies in the fully developed system.

(d) Class III incorporate all cases of fusion defects. The term dysfusion comes from the addition of the Greek origin "dys" to the English "fusion" to describe the abnormal fusion of the two uterine sides during embryologic development. In this main class all cases of formerly described didelphys and bicornuate uterus are included. This enables us to create a more embryological clear category without "transitional" cases [62].

Thus, a dysfused uterus is characterized as any uterus with an abnormal outline at the level of uterine midline.
As can easily be imagined, it is also associated with an inner indentation at the midline level (septum) that divides the cavity. An abnormal uterine outline is defined as any fundal indentation exceeding half of the uterine wall thickness at the midline level and reaching up to the full separation of the uterus into two distinct hemi-uterus (formerly didelphys uterus).

Class III is further divided into two subclasses according to the degree of the uterine body deformity (uterine corpus, including or not the cervix): (a) partial dysfused uterus is characterized by an outer form indentation at the level of uterine midline partially dividing uterine corpus above the level the cervix; (b) complete dysfused uterus is characterized by an outer form indentation at the level of uterine midline fully dividing uterine corpus up to the level of the cervix. Cases with cervical (double cervix/ formerly didelphys uterus) and/or vaginal defects (e.g., didelphys uterus with obstructing or not vaginal septum) [22, 63-72] could be sub-classified in the fully developed system with the addition of cervical and/or vaginal congenital anomalies.

A general subcategory of Class III is dysfused "septate" uterus. In these cases, fusion defects come together with absorption defects. A dysfused "septate" uterus is defined as any dysfused uterus in which the width at the midline uterine fundus' level exceeds by $50 \%$ that of the uterine wall thickness (e.g., if the uterine wall thickness is by mean $10 \mathrm{~mm}$ as dysfused "septate" uterus is characterized as any thickness in the midline indentation $>15 \mathrm{~mm}$ ). The necessity of creating this distinct subcategory comes from the fact that these cases can be 
partially treated by hysteroscopic septum resection. Furthermore, this subcategory is included in the class of dysfused uterus since: (1) by definition, any abnormal outline defect is included in this category (accuracy of definition); (2) the result of hysteroscopic treatment is a "clear" dysfused uterus; and (3) during hysteroscopic treatment to avoid complications (uterine rupture), underlining of the abnormal external outline is clinically important.

(e) Class $I V$ incorporates all cases of unilateral formed uterus with aplasia or dysplasia of the other uterine half. It is a formation defect, but the necessity of classifying it separately from full aplasia comes from the presence of a fully developed functional uterine hemicavity, which does not exist in cases of aplasia.

A more simple subdivision is also chosen for Class IV compared to that in the ASRM classification system; it is divided into two sub-classes based on the presence/absence of a cavity in an existing rudimentary horn, since the presence of the cavity is the most important factor for certain complications such as ectopic pregnancy in the rudimentary horn or hematocavity [73-78]. Furthermore, treatment is only indicated in cases of patients having a rudimentary horn with cavity (laparoscopic removal) [79, 80].

It should be noted that the name of this class is derived from the normally developed horn, whereas the name of the subclasses are attributed to the characteristics of the abnormally developed horn.

(f) Class $V$ incorporates only cases of uterine aplasia/dysplasia (formation defect) and is thus designed as a "clear" category [21, 50, 81-92]. As already mentioned, cases with cervical, vaginal or adnexal aplasia/dysplasia (having different embryological origin, clinical presentation, prognosis and treatment) can be classified in separate categories or sub-categories of the fully developed new classification system. The term "dysplasia" has a Greek origin, and it means abnormally developed uterus, which fits in cases with non-functional developed parts of the uterus. As a synonym, the term "dysgenesis" can be used; this also means abnormal formation.

Class V is further divided into two subclasses based on the presencelabsence of a cavity in an existing rudimentary horn, avoiding an extremely detailed subdivision $[21,45,85,91,93,94]$. This criterion is chosen because this seems to be a clinically significant parameter for patient's management: the presence of a cavity could be combined with complications such as "hemato-cavity" $[37,95]$ and gives the possibility to restore anatomical continuity after neovagina formation with isthmoneovagina anastomosis [37, 85, 94].

(g) Finally, Class VI is reserved for still unclassified cases. Modern imaging technology (ultrasound and/or magnetic resonance imaging) can provide objective estimation of uterine anatomy for the needs of differential diagnosis between the six groups. However, rare anomalies, subtle changes or combined pathology may likely not to be allocated correctly to one of the six groups [96]; for these cases, in order to keep the groups "clear", a sixth class is created.

Comments on the proposed classification of uterine anomalies

In the presented classification system, arcuate uterus is deleted as a separate entity, since by definition (ASRM classification) it has no clinical significance [17]. Furthermore, all these years a great confusion has existed between arcuate and septate uteri (which are the anatomical borders), and some terms such as small septae have been also used to describe cases of arcuate (?) uterus with clinical significance in prognosis [23, 97, 98]. Hence, for the needs of clarity of the new system, only septate uterus has been included as a different class coming from an absorption defect.

An effort has been made to have clear and accurate definitions based on uterine anatomy. The degree of uterine cavity deformity has been chosen for the sub-classification of dysfused and septate uterus; any deformity reaching up to the cervix is defined as complete and any other as partial. However, another important criterion, which could be taken into account, is patient's prognosis. Thus, it is extremely important in the fore coming studies to have a clear reference to the uterus anatomical situation in order to decide what is clinically important and what not.

\section{Imaging techniques for the diagnosis of uterine anomalies}

Anatomy is the basis of the new system. Thus, diagnosis of uterine anomalies should be based on diagnostic modalities that could determine the anatomical status of the female genital tract on a more objective way [99]. The ideal diagnostic method should provide objective and measurable information on the anatomical status of the uterus in a non-invasive way

The available diagnostic methods that can be used in the investigation of the patient are as follows:

1. Gynecological examination $(G E)$. It should be noticed that gynaecological examination is very important in the diagnostic work-up of the patients with congenital malformations. Vaginal malformations (aplasia, septum) and some cervical malformations could be diagnosed objectively mainly with inspection. Furthermore, palpation through the vagina and/or the rectum (in cases of 
vaginal aplasia) could provide useful but not always objective information.

2. Two-dimensional ultrasound ( $2 D$ US). This mainly transvaginal approach provides objective and, importantly, measurable information for the cervix, the uterine cavity, the uterine wall and the external contour of the uterus. It is very popular and accessible, non-invasive, but its accuracy highly depends on the experience of the examiner and on the examination methodology followed [100-102].

3. Sonohysterography (SHG). Compared to 2D US, this method has the additional advantage of offering a better imaging of the uterine cavity, thus enhancing the accuracy in identifying the anatomy of the female genital tract and especially that of the uterus [103-110].

4. Hysteroscopy (Hys) is the gold standard for the examination of the cervical canal and the uterine cavity. However, as it does not provide information on the myometrial layer, hysteroscopy alone could not be used for the differential diagnosis between different groups. Nowadays, with the use of normal saline as distension medium and the miniaturization of the rigid scopes, hysteroscopy has become a minimally invasive screening tool, well tolerated by the patients and feasible for gynaecologists [34, 111, 112].

The combination of 2D US, SHG and hysteroscopy is proposed as the current standard, one "stop", evaluation protocol for the screening and diagnosis of uterine anomalies.

1. Three-dimensional ultrasound ( $3 D U S$ ) provides an ideal, objective and measurable representation of the examined organs [113-120]. It provides information on the cervix, the uterine cavity, the uterine wall, the external contour of the uterus and the other structures with the exception of tubes. Theoretically, it seems to be an ideal method for the diagnostic approach of the uterus.

2. Magnetic resonance imaging seems to be a very useful diagnostic tool, since it can provide detailed information on the anatomical status of the female genital tract [114, 121-124]. Contrary to the visualization in ultrasound, in MRI myometrium is not seen as a homogeneous smooth muscle mass but is divided into two different structural and functional entities: the internal myometrium or junctional zone (JZ), ontogenetically related to endometrium and functionally important for reproduction, and the outer myometrium which is seen as a larger hypodense zone [125-128]. It should be noted that MRI is expensive, and its validity in the diagnosis of congenital malformations is under investigation. Until now, it has not been used as a primary diagnostic tool but was applied mainly for the investigation of complex anomalies [117, 129-132].

3. Hysterosalpingography has been and is still frequently the primary and only non-invasive diagnostic tool used for the diagnosis of uterine's cavity deformations. It cannot provide any information on the uterine wall and the external contour of the uterus [3, 133-135]. In order to overcome this serious limitation, Ott et al. [136] proposed the use of the angle formed by the hemicavities for the needs of differential diagnosis. It should also be noted that the quality of HSG is highly dependent on the examiner: both the examination performance and image interpretation have to be done preferably by a gynaecologist, which is not always feasible in daily practice: for example, in cases of double cervices to catheterize both of them and during the examination to pull the uterus for the best imaging of the uterine cavity [137]. Obviously, ultrasound provides superior quality information than HSG.

4. Laparoscopy and Hysteroscopy (Lap/Hys). The combined application of these endoscopic techniques is thought to be the gold standard in the investigation of women with congenital malformations and especially the uterine ones [138]. However, the diagnosis is mainly based on the subjective impression of the clinician performing them, and this is thought to be a limitation in the objective estimation of the anomaly [15].

The specificity and sensitivity of the above-mentioned methods in the investigation of patients with uterine malformations have been recently reviewed [3]. Based on their diagnostic accuracy, the diagnostic methods have been categorized into four categories:

Class Ia - Those that are capable of identifying congenital uterine anomalies and classifying them into appropriate sub-types with an accuracy of $>90 \%$. Hysteroscopy plus laparoscopy, SHG and 3D US belong to this class, Class $\mathrm{Ib}$ - Those that are capable of identifying congenital uterine anomalies with an accuracy of $>90 \%$ without being able to classify them into appropriate sub-types. Hysteroscopy alone belongs to this class.

Class II - Those that are capable of identifying congenital uterine anomalies with an accuracy of $<90 \%$. According to the available data, HSG and 2D US belong to this class.

Class III - This includes the investigations whose diagnostic accuracy in identifying congenital uterine anomalies is still not exactly known. MRI belongs to this class.

It seems, therefore, that a wide variety of diagnostic tests are available for the interpretation of the female genital tract anatomy with different diagnostic properties as well as variable diagnostic accuracy. Thus, based on the clinical presentation of the patient, the clinician should start with gynaecological examination. HSG cannot be considered as a first line diagnostic tool, and should be used under specific conditions only. Nowadays, transvaginal 2D US seems to be 
the basic imaging method: it is simple, available in almost every outpatient clinic, and can give reliable, reproducible and measurable information on uterine anatomy for exact diagnosis and differential diagnosis between the different categories. Enlargement of the examination with SHG and ambulatory mini-hysteroscopy seems reasonable since they can provide additional information; they are office procedures with low risk and high patient satisfaction rates.

Further detailed information on uterine anatomy can be obtained with the use of 3D US. A disadvantage for its widespread use is that it is not available everywhere, is more expensive and can be used only by experienced personnel. MRI has comparable diagnostic accuracy with that of 3D US and provides supplementary information on the two structurally and functionally different zones of the myometrium. At the moment, its use is limited depending on the safety regulations of each country, and should be kept for research, especially for cases of complex anomalies or for cases where 3D US is necessary but unavailable or has failed to give an objective estimation of the female genital tract anatomy.

However, for the needs of patients' grouping according to the new system, a clear and exact representation of the female's genital tract anatomy is the desired result of a successful diagnostic work-up. Nowadays, endoscopic techniques (laparoscopy and hysteroscopy) should be kept mainly for the patient's treatment or for the elucidation of extremely rare and unclassified cases [139].

\section{Conclusion}

Congenital malformations of the female genital tract are a common entity with an estimated prevalence of $4-7 \%$. The need for a new updated classification has been already underlined since currently available systems are associated with various limitations in effective categorization of the anomalies. The EAGS has established a scientific project on this issue, aiming to critically evaluate the current situation and to prepare the scientific basis for a new system. This initiative has been adopted by the recently established common ESHRE/ESGE working group of experts (CONUTA group). Consensus for the development of a new classification system should be reached using the Delphi procedure.

A new clinical approach for the classification of uterine anomalies is proposed. Uterine anatomy is the basis of the new system. Embryological origin has been adopted as the secondary basic characteristic in the design of the main classes. The system is open for further development including further subdivisions based on cervical and vaginal anatomical varieties in order to be more comprehensive. The new proposed system takes into account the experience gained from the currently available classification systems mainly that of the AFS. It is simple, clear and accurate in its definitions. It could be used as the starting point for the working group of experts in the field.

Declaration of interest The authors report no conflicts of interest. The authors alone are responsible for the content and writing of the paper.

Open Access This article is distributed under the terms of the Creative Commons Attribution Noncommercial License which permits any noncommercial use, distribution, and reproduction in any medium, provided the original author(s) and source are credited.

\section{References}

1. Chan YY, Jayaprakasan K, Zamora J, Thornton JG, Raine-Fenning N, Coomarasamy A (2011) The prevalence of congenital uterine anomalies in unselected and high-risk populations: a systematic review. Hum Reprod Update 17:761-771

2. Grimbizis GF, Camus M, Tarlatzis BC, Bontis JN, Devroey P (2001) Clinical implications of uterine malformations and hysteroscopic treatment results. Hum Reprod Update 7:161-164

3. Saravelos SH, Cocksedge KA, Li T-C (2008) Prevalence and diagnosis of congenital uterine anomalies in womwn with reproductive failure: a critical appraisal. Hum Reprod Update 14:415-419

4. Grimbizis GF, Campo R (2010) Congenital malformations of the female genital tract: the need for a new classification system. Fertil Steril 94:401-407

5. Acien P (1993) Reproductive performance of women with uterine malformations. Hum Reprod 8:122-126

6. Heller-Boersma JG, Schmidt UH, Edmonds DK (2007) A randomized controlled trial of a cognitive-behavioural group intervention versus waiting-list control for women with uterovaginal agenesis (Mayer-Rokitansky-Kuster-Hauser syndrome: MRKH). Hum Reprod 22:2296-2301

7. Heinonen PK, Saarikoski S, Pystynen P (1982) Reproductive performance of women with uterine anomalies. An evaluation of 182 cases. Acta Obstet Gynecol Scand 61:157-162

8. Giannesi A, Marchiole P, Benchaib M, Chevret-Measson M, Mathevet P, Dargent D (2005) Sexuality after laparoscopic Davydov in patients affected by congenital complete vaginal agenesis associated with uterine agenesis or hypoplasia. Hum Reprod 10:2954-2957

9. Lin PC, Bhatnagar KP, Nettleton GS, Nakajima ST (2002) Female genital anomalies affecting reproduction. Fertil Steril 78:899-915

10. Mollo A, De Franciscis P, Colacurci N, Cobellis L, Perino A, Venezia R, Alviggi C, De Placido G (2009) Hysteroscopic resection of the septum improves the pregnancy rate of women with unexplained infertility: a prospective controlled trial. Fertil Steril 91:2628-2631

11. Morgan EM, Quint EH (2006) Assessment of sexual functioning, mental health and life goals in women with vaginal agenesis. Arch Sex Behav 35:607-618

12. Rackow BW, Arici A (2007) Reproductive performance of women with Mullerian anomalies. Curr Opin Obstet Gynecol 19:229-237

13. Raga F, Bauset C, Remohi J, Bonilla-Musoles F, Simon C, Pellicer A (1997) Reproductive impact of congenital Mullerian anomalies. Hum Reprod 12:2277-2281

14. Sonmezer M, Taskin S, Atabekoglou C, Gungor M, Unlu C (2006) Laparoscopic management of rudimentary uterine horn pregnancy: case report and literature review. JSLS 10:396-399 
15. Woelfer B, Salim R, Banerjee S, Elson J, Regan L, Jurkovic D (2001) Reproductive outcomes in women with congenital uterine anomalies detected by three-dimensional ultrasound screening. Obstet Gynecol 98:1099-1103

16. Zlopasa G, Skrablin S, Kalafatic D, Banovic V, Lesin J (2007) Uterine anomalies and pregnancy outcome following resectoscope metroplasty. Int J Gynecol Obstet 98:129-133

17. American Fertility Society (1988) The AFS classification of adnexal aghesions, distul tubal occlusion, tubal occlusion secondary to tubal ligation, tubal pregnancies, Mullerian anomalies and intrauterine adhesions. Fertil Steril 49:944-955

18. Buttram VC, Gibbons WE (1979) Mullerian anomalies: a proposed classification (an analysis of 144 cases). Fertil Steril 32:40-46

19. Acien P, Acien M, Sanchez-Ferrer M (2004) Complex malformations of the female genital tract. New types and revision of classification. Hum Reprod 19:2377-2384

20. Acien P, Acien MI (2011) The history of female genital tract malformation classifications and proposal of an updated system. Hum Reprod Update 17:693-705

21. Oppelt P, Renner SP, Brucker S, Strissel PL, Strick R, Oppelt PG, Doerr HG, Schott GE, Hucke J, Wallwiener D, Beckmann MW (2005) The VCUAM (Vagina Cervix Uterus Adnex Associated Malformation) classification: a new classification for genital malformations. Fertl Steril 84:1493-1497

22. Burgis J (2001) Obstructive Mullerian anomalies: case report, diagnosis and management. Am J Obstet Gynecol 185:338-344

23. Gubbini G, Di Spiezio SA, Nascetti D, Marra E, Spinelli M, Greco E, Casadio P, Nappi C (2009) New outpatient subclassification system for American Fertility Society classes V and VI uterine anomalies. J Minim Invasive Gynecol 16:554-561

24. Joki-Erkkilä MM, Heinonen PK (2003) Presenting and long-term clinical implications and fecundity in females with obstructing vaginal malformations. J Pediatr Adolesc Gynecol 16:307-312

25. Rock JA, Carpenter SE, Wheeless CR, Jones HWJ (1995) The clinical management of maldevelopment of the uterine cervix. J Pelvic Surg 1:129-133

26. Rock JA, Roberts CP and Jones HW (2010) Congenital anomalies of the uterine cervix: lessons from 30 cases managed clinically by a common protocol. Fertil Steril 94:1858-1863

27. Strawbrigde LC, Crough NS, Cutner AS, Creighton SM (2007) Obstructive Mullerian anomalies and modern laparoscopic management. J Pediatr Adolesc Gynecol 20:195-200

28. Akar ME, Bayar D, Yildiz S, Ozel M, Gilmaz Z (2005) Reproductive outcome of women with unicornuate uterus. Aus N Z J Obstet Gynecol 54:148-150

29. Colacursi N, De Franciscis P, Mollo A, Litta P, Perino A, Cobellis L, De Placido G (2007) Small-diameter hysteroscopy with Versapoint versus resectoscopy with unipolar knife for the treatment of septate uterus: a prospective randomized study. J Minim Invasive Gynecol $14: 622-627$

30. Garcia-Enguidanos A, Calle ME, Valero J, Luna S, Dominguez-Rojas V (2002) Risk factors in miscarriage: a review. Eur J Obstet Gynecol Reprod Biol 102:111-119

31. Grimbizis G, Camus M, Clasen K, De Munck L, Devroey P (1998) Hysteroscopic septum resection in patients with recurrent abortions or infertility. Hum Reprod 13:1188-1193

32. Pabuccu R, Gomel V (2004) Reproductive outcome after hysteroscopic metroplasty in women with septate uterus and otherwise unexplained infertility. Fertil Steril 81:1675-1678

33. Aittomaki K, Eroila H, Kajanoja P (2001) A population-based study of the incidence of Müllerian aplasia in Finland. Fertil Steril 76:624-625

34. Campo R, Van Belle Y, Rombauts L, Brosens I, Gordts S (1999) Office mini-hysteroscopy. Hum Reprod Update 5:73-81

35. Acien P (1992) Embryological observations on the female genital tract. Hum Reprod 7:437-445
36. Ashton D, Amin HK, Richard RM, Neuwirth RS (1988) The incidence of asymptomatic uterine anomalies in women undergoing transcervical tubal sterilization. Obstet Gynecol 72:2830

37. Acien P, Acien MI, Quereda F, Santoyo T (2008) Cervicovaginal agenesis: spontaneous gestation at term after previous re-implantation of the uterine corpus in a neovagina: case report. Hum Reprod 23:548-553

38. Alborzi S, Momtahan M, Parsanezhad ME, Yazdani M (2008) Successful treatment of cervical aplasia using a peritoneal graft. Int J Gynecol Obstet 88:299-302

39. Bedner R, Rzepka-Gorska I, Blogowska A, Malecha J, Kosmider M (2004) Effects of a surgical treatment of congenital cervicovaginal agenesia. J Pediatr Adolesc Gynecol 17:327-330

40. Bugmann P, Amaudruz M, Hanquinet S, La Scala G, Birraux J, Le Coultre C (2002) Uterocervicoplasty with a bladder mucosa layer for the treatment of complete cervical agenesis. Fertil Steril 77:831-835

41. Connolly G, Devaney D, McKenna P (2004) A case of cervical dysgenesis. J Obstet Gynecol 24:322-333

42. Creighton SM, Davies MC, Cutner A (2006) Laparoscopic management of cervical agenesis. Fertil Steril 85:1510.e13-15

43. Deffarges JV, Haddad B, Musset R, Paniel BJ (2001) Uterovaginal anastomosis in women with uterine cervix atresia: longterm follow-up and reproductive performance. A study of 18 cases. Hum Reprod 16:1722-1725

44. Ding D-C, Hsu S, Liu J-Y (2005) Vaginal agenesis in a girl with normal uterus and cervix reconstructed with vulvar skin graft. Eur J Obstet Gynecol Reprod Biol 123:257-258

45. Fedele L, Bianchi S, Frontino G, Berlanda N, Montefusco S, Borruto F (2008) Laparoscopically assisted uterovesticular anastomosis in patients with uterine cervix atresia and vaginal aplasia. Fertil Steril 89:212-216

46. Fujimoto VY, Miller JH, Klein NA, Soules (1997) Congenital cervical atresia: report of seven cases and review of the literature. Am J Obstet Gynecol 177:1419-1425

47. Grimbizis GF, Tsalikis T, Mikos T, Papadopoulos N, Tarlatzis BC, Bontis JN (2004) Successful end-to-end cervico-cervical anastomosis in a patient with congenital cervical fragmentation: case report. Hum Reprod 19:1204-1210

48. Jasonni VM, La Marca A, Matonti G (2007) Utero-vaginal anastomosis in the treatment of cervical atresia. Acta Obstet Gynecol Scand 86:1517-1518

49. Kresowik J, Ryan GL, Austin C, Van Voorhis BJ (2007) Ultrasoundassisted repair of a unique case of distal vaginal agenesis. Fertil Steril 87:976.e9-12

50. Miller RJ, Breech LL (2008) Surgical correction of vaginal anomalies. Clin Obstet Gynecol 51:223-236

51. Selvaggi G, Monstrey S, Depypere H, Blondeel P, Van Landuyt K, Hamdi M, Dhont M (2003) Creation of a neovagina with the use of a pudendal thigh fasciocutaneous flap and restoration of uterovaginal continuity. Fertil Steril 80:607-611

52. Shirota K, Fukuoka M, Hiroshi Tsujioka H, Inoue Y, Kawarabayashi $\mathrm{T}$ (2009) A normal uterus communicating with a double cervix and the vagina: a Mullerian anomaly without any present classification. Fertil Steril 91:935.e1-e3

53. Sparac V, Stilinovic K, Ilijas M, barcot Z, Kupesic S, Prka M, Bauman R, Kurjak A (2004) Vaginal aplasia associated with anatomically and functionally normal uterus. Eur J Obstet Gynecol Reprod Biol 115:110-112

54. Troiano RN, McCarthy SM (2004) Müllerian duct anomalies: imaging and clinical issues. Radiology 233:19-34

55. Chang AS, Siegel CL, Moley KH, Ratts VS, Odem RR (2004) Septate uterus with cervical duplication and longitudinal vaginal septum: a report of five new cases. Fertil Steril 81:11331136 
56. Duffy DA, Nulsen J, Maier D, Schmidt D, Benadiva C (2004) Septate uterus with cervical duplication: a full-term delivery after resection of a vaginal septum. Fertil Steril 81:1125-1126

57. Heinonen PK (2006) Complete septate uterus with longitudinal vaginal septum. Fertil Steril 85:700-705

58. Hur J-Y, Shin J-H, Lee J-K, Oh M-J, Saw H-S, Park Y-K, Lee KW (2007) Septate uterus with double cervices, unilaterally obstructed vaginal septum and ipsilateral renal agenesis: a rare combination of Mullerian and Wolffian anomalies complicated by severe endometriosis in an adolescent. J Minim Invasive Gynecol 14:128-131

59. Patton PE, Novy MJ, Lee DM, Hickok LR (2004) The diagnosis and reproductive outcome after surgical treatment of the complete septate uterus, duplicated cervix and vaginal septum. Am J Obstet Gynecol 190:1669-1678

60. Parsanezhad ME, Alborzi S, Zarei A, Dehbashi S, Shirazi LG, Rajaeefard A, Schmidt EH (2006) Hysteroscopic metroplasty of the complete uterine septum, duplicate cervix and vaginal septum. Fertil Steril 85:1473-1477

61. Pavone ME, King JA, Vlahos N (2006) Septate uterus with cervical duplication and a longitudinal vaginal septum: a Mullerian anomaly without a classification. Fertil Steril 85:494.e9-10

62. Acien P, Acien M and Sanchez-Ferrer ML (2008) Mullerian anomalies "without a classification": from the didelphysunicollis uterus to the bicervical uterus with or without septate vagina. Fertil Steril 91:2369-2375

63. Acien P, Sanchez-Ferrer M, Mayol-Belda M-J (2004) Unilateral cervico-vaginal atresia with ipsilateral renal agenesis. Eur J Obstet Gynecol Reprod Biol 117:249-251

64. Ballesio L, Andreoli C, De Cicco ML, Angeli ML, Manganaro L (2003) Hematocolpos in double vagina associated with uterus didelphys: US and MRI findings. Eur J Radiol 45:150-153

65. Coskun A, Okur N, Ozdemir O, Kiran G and Arykan DC (2008) Uterus didelphys with an obstructed unilateral vagina by a transverse vaginal septum associated with ipsilateral renal agenesis, duplication of inferior vena cava, high-riding aortic bifurcation and intestinal malrotation a case report. Fertil Steril 90:2006.e9-11

66. Growdon WB, Laufer MR (2008) Uterine didelphys with duplicated upper vagina and bilateral lower vaginal agenesis: a novel Müllerian anomaly with options for surgical management. Fertil Steril 89:693-698

67. Kumar S, Singh SK, Mavuduru R, Naveen A, Agarwal MM, Vanita J, Mandal AK (2008) Bicornuate uterine horns with complete cervico-vaginal agenesis and congenital vesicouterine fistula. Int Urogynecol J 19:739-741

68. Levsky MJ, Mondshine RT (2006) Hematometrocolpos due to imperforate hymen in a patient with bicornuate uterus. AJR 186:1469-1470

69. Madureira AJ, Mariz CM, Bernardes JC, Ramos IM (2006) Uterus didelphys with obstructing hemivaginal septum and ipsilateral renal agenesis. Radiology 239:602-606

70. Tsai C-H, Chen C-P, Chang MD-T, Chang S-J, Chien S-C (2007) Hematometrocolpos secondary to didelphys uterus and unilateral imperforated double vagina as an unusual cause of acute abdomen. Taiwan J Obstet Gynecol 46:448-452

71. Vercellini P, Daguati R, Somigliana E, Vigano P, Lanzani A, Fedele L (2007) Asymmetric lateral distribution of obstructed hemivagina and renal agenesis in women with uterus didelphys: institutional case series and a systematic literature review. Fertil Steril 87:719-724

72. Zurawin RK, Dietrich JE, Heard MJ, Edwards CL (2004) Didelphic uterus and obstructed hemivagina with renal agenesis: case report and review of the literature. J Pediatr Adolesc Gynecol $17: 137-141$

73. Arshad Z, Mohan S (2005) Pregnancy in a non-communicating uterine horn. Acta Obstet Gynecol Scand 84:1023
74. Arslan T, Bilgic E, Senturk B, Yusel N (2009) Rudimentary uterine horn pregnancy: a mystery diagnosis. Fertil Steril 92:2037.e1-e3

75. Cutner A, Saridogan E, Hart R, Pandya P, Creighton S (2004) Laparoscopic management of pregnancies occurring in noncommunicating accessory uterine horns. Eur J Obstet Gynecol Reprod Biol 113:106-109

76. Heinonen PK (1997) Unicornuate uterus and rudimentary horn. Fertil Steril 68:224-230

77. Khanapure A, Aravind S, Lawley R, Verwood G (2005) Rupture of a pregnancy in the rudimentary communicating horn of the uterus. J Obstet Gynecol 25:310-311

78. Tang R, Sheng Y, Chen ZJ (2004) Rupture of pregnancy in a communicating rudimentary uterine horn after in vitro fertilization and embryo transfer. Int J Gynecol Obstet 86:394-395

79. Fedele L, Bianchi S, Zanconato G, Berlanda N, Bergamini V (2005) Laparoscopic removal of the cavitated noncommunicating rudimentary uterine horn: surgical aspects in 10 cases. Fertil Steril 83:432-436

80. Theodoridis TD, Saravelos H, Chatzigeorgiou KN, Zepiridis L, Grimbizis GF, Vavilis D, Loufopoulos A, Bontis JN (2006) Laparoscopic management of unicornuate uterus with non-communicating rudimentary horn (three cases). RBM Online 12:126-128

81. Brun J-L, Belleannee G, Grafeille N, Aslan A-F, Brun GH (2002) Long-term results after neovagina creation in Mayer-RokitanskyKuster-Hauser syndrome by Vecchietti's operation. Eur J Obstet Gynecol Reprod Biol 103:168-172

82. Cai B, Zhang JR, Xi XW, Yan Q, Wan XP (2007) Laparoscopically assisted sigmoid colon vaginoplasty in women with MayerRokitansky-Kuster-Hauser syndrome: feasibility and short-term results. BJOG 114:1486-1492

83. Darai E, Toullalan O, Besse O, Potiron L, Delga P (2003) Anatomic and functional results of laparoscopic-perineal neovagina construction by sigmoid colpoplasty in women with Rokitansky's syndrome. Hum Reprod 11:2454-2459

84. Darwish AM (2007) A simplified novel laparoscopic formation of neovagina for cases of Mayer-Rokitansky-Kuster-Hauser syndrome. Fertil Steril 88:1427-1430

85. Fedele L, Bianchi S, Berlanda N, Bulfoni A, Fontana E (2006) Laparoscopic creation of a neovagina and recovery of menstrual function in a patient with Rokitansky syndrome: a case report. Hum Reprod 21:3287-3289

86. Fedele L, Bianchi S, Berlanda N, Fontana E, Raffaelli R, Bulfoni A, Braidotti P (2006) Neovaginal mucosa after Vecchietti's laparoscopic operation for Rokitansky syndrome: structural and ultrastructural study. Am J Obstet Gynecol 195:56-61

87. Fedele L, Bianchi S, Frontino G, Ciappina N, Fontana E, Borruto F (2007) Laparoscopic findings and pelvic anatomy in Mayer-Rokitansky-Kuste-Hauser syndrome. Obstet Gynecol 109:1111-1115

88. Fedele L, Frontino G, Restelli E, Giappina N, Motta F, Bianchi S (2010) Creation of a neovagina by Davydov's laparoscopic modified technique in patients with Rokitansky syndrome. Am J Obstet Gynecol 202:33.e1-e6

89. Guerrier D, Mouchel T, Pasquier L, Pellerin I (2006) The MayerRokitansky-Kuster-Hauser syndrome (congenital absence of uterus and vagina) - phenotypic manifestations and genetic approaches. J Nedat Results Biomed 5:1-8

90. O'Connor JL, DeMarco RT, Pope JC, Adams MC, Brock JW (2004) Bowel vaginoplasty in children: a retrospective review. J Pediatr Surg 39:1205-1208

91. Oppelt P, Renner SP, Kellermann A, Brucker S, Hauser GA, Ludwig KS, Strissel PL, Strick R, Wallwiener D, Beckmann MW (2006) Clinical aspects of Mayer-Rokitansky-KuesterHauser syndrome: recommendations for clinical diagnosis and staging. Hum Reprod 21:792-797 
92. Seccia A, Salgarello M, Sturla M, Latorre S, Farallo E (2002) Neovaginal reconstruction with the modified McIndoe technique: a review of 32 cases. Ann Plast Surg 49:379-384

93. Goluda M, Gabrys MSt, Ujec M, Jedryka M, Goluda C (2006) Bicornuate rudimentary uterine horns with functioning endometrium and complete cervical-vaginal agenesis coexisting with ovarian endometriosis: a case report. Fertil Steril 86:462.e9-e11

94. Grimbizis GF, Papanicolaou A, Papadopoulos N, Theodoridis Th, Papadopoulos M, Tarlatzis BC (2010) The chance for a successful isthmo-neovagina anastomosis after Davydov's neovagina formation. Gynaecol Surg 7(Suppl 1):S80

95. Takeuchi H, Sato Y, Shimanuki H, Kikuchi J, Kitase M, Kinoshita K (2006) Accurate preoperative diagnosis and laparoscopic removal of the cavitated non-communicated uterine horn for obstructive Mullerian anomalies. J Obstet Gynecol Res 32:74-79

96. Sadik S, Taskin O, Sehirali S, Mendilcioglu I, Onoglu AS, Kursun S, Wheeler J (2002) Complex Mullerian malformations: report of a case with hypoplastic non-cavitated uterus and two rudimentary horns. Hum Reprod 17:1343-1344

97. Mucowski SJ, Herndon CN, Rosen MP (2010) The arcuate anomaly: a critical appraisal of its diagnostic and clinical relevance. Obstet Gynecol Surv 65:449-454

98. Tomazevic T, Ban-Frangez H, Ribic-Pucelj M, Premru-Srsen T, Verderik I (2007) Small uterine septum is an important risk variable for preterm birth. Eur J Obstet Gynecol Reprod Biol 135:154-157

99. Dee Olpin J, Heilbrun M (2009) Imaging of Mullerian duct anomalies. Clin Obstet Gynecol 52:40-56

100. Kupesic S (2001) Clinical implications of sonographic detection of uterine anomalies for reproductive outcome. Ultrasound Obstet Gynecol 18:387-400

101. Lindheim SR, Adsuar N, Kushner DM, Pritts EA, Olive DL (2003) Sonohysterography: a valuable tool in evaluating the female pelvis. Obstet Gynecol Surv 58:770-784

102. Mazouni C, Girard G, Deter R, Haumonte J-B, Blanc B, Bretelle F (2008) Diagnosis of Mullerian anomalies in adults: evaluation of practice. Fertil Steril 89:219-222

103. Alborzi S, Dehbashi S, Parsanezhad ME (2002) Differential diagnosis of septate and bicornuate uterus by sonohysterography eliminates the need for laparoscopy. Fertil Steril 78:176-178

104. Cepni I, Ocal P, Erkan S, Saricalli FS, Akbas H, Demirkiran F, Idil M, Bese T (2005) Comparison of transvaginal sonography, saline infusion sonography and hysteroscopy in the evaluation of uterine cavity pathologies. ANZJ Obstet Gynecol 45:30-35

105. Grimbizis GF, Tsolakidis D, Mikos T, Anagnostou E, Asimakopoulos E, Stamatopoulos P, Tarlatzis BC (2010) A prospective comparison of transvaginal ultrasound, saline infusion sonohysterography, and diagnostic hysteroscopy in the evaluation of endometrial pathology. Fertil Steril 94:2720-2795

106. Guimarães Filho HA, Mattar R, Pires CR, Araujo Junior E, Moron AF, Nardozza LMM (2006) Comparison of hysterosalpingography, hysterosonography and hysteroscopy in evaluation of the uterine cavty in patients with recurrent pregnancy losses. Arch Gynecol Obstet 274:284-288

107. Guven MA, Bese T, Demirkiran F, Idil M, Mgoyi L (2004) Hydrosonography in screening for intracavitary pathology in infertile women. Int J Gynecol Obstet 86:377-383

108. Shokeir S, Abdelshaheed M (2009) Sonohysterography as a firstline evaluation for uterine abnormalities in women with recurrent failed in vitro fertilization-embryo transfer. Fertil Steril 91(suppl 4):1321-1322

109. Tur-Kaspa I, Gal M, Hartman M, Hartman J, Hartman A (2006) A prospective evaluation of uterine abnormalities by saline infusion sonohysterography in 1009 women with infertility or abnormal uterine bleeding. Fertil Steril 86:1731-1735
110. Valenzano MM, Mistrangelo E, Lijoi D, Fortunato T, Lantieri PB, Risso D, Costantini S, Ragni N (2006) Transvaginal sonohysterographic evaluation of uterine malformations. Eur J Obstet Gynecol Reprod Biol 124:246-249

111. Bettocchi S, Ceci O, Nappi L, Pontrelli G, Pinto L, Vicino M (2007) Office hysteroscopic motroplasty: three "diagnostic criteria" to differentiate between septate and bicornuate uteri. J Minim Invasive Gynecol 14:324-328

112. Gordts S, Campo R, Puttemans P, Verhoven H, Gianaroli L, Brosens J, Brosens I (2002) Investigation of the infertile couple: a one stop outpatient endoscopy-based approach. Hum Reprod 17:1684-1687

113. Ayoubi J-M, Fanchin R, Ferretti G, Pons J-C, Bricault I (2002) Three-dimensional ultrasonographic reconstruction of the uterine cavity: toward virtual hysteroscopy? Eur Radiol 12:2030-2033

114. Bermejo C, Ten Martinez P, Cantarero R, Diaz D, Perez Pedregosa J, Barro E, Labrador E, Ruiz Lopez L (2010) Three-dimensional ultrasound in the diagnosis of Mullerian duct anomalies and concordance with magnetic resonance imaging. Ultrasound Obstet Gynecol 35:593-601

115. Caliskan E, Ozkan S, Cakiroglu Y, Sarisoy HT, Corakci A, Ozeren S (2010) Diagnostic accuracy of real-time 3D sonography in the diagnosis of congenital Mullerian anomalies in high-risk patients with respect to the phase of the menstrual cycle. J Clin Ultrasound 38:123-127

116. Ghi T, Casadio P, Kuleva M, Perrone AM, Savelli L, Giunchi S, Meriggiola C, Gubbini G, Pilu G, Pelusi C, Pelusi G (2009) Accuracy of three-dimensional ultrasound in diagnosis and classification of congenital uterine anomalies. Fertil Steril 92:808-813

117. Imai A, Takagi H, Matsunami K (2004) Double uterus associated with renal aplasia; magnetic resonance appearance and threedimensional computed tomographic urogram. Int J Gynecol Obstet 87:169-171

118. Jurkovic D (2002) Three-dimensional ultrasound in gynecology: a critical evaluation. Ultrasound Obstet Gynecol 19:109-117

119. Raine-Fenning N, Fleischer AC (2005) Clarifying the role of three-dimensional transvaginal sonography in reproductive medicine: an evidence-based appraisal. J Exper Clin Ass Reprod 2:10

120. Salim R, Woelfer B, Backos M, Regan L, Jurkovic D (2003) Reproducibility of three-dimensional ultrasound diagnosis of congenital uterine anomalies. Ultrasound Obstet Gynecol 21:578-582

121. Church DG, Vancil JM, Vasanawala SS (2009) Magnetic resonance imaging for uterine and vaginal anomalies. Curr Opin Obstet Gynecol 21:379-389

122. Marten K, Vosshenrich R, Funke M, Obenauer S, Baum F, Grabbe E (2003) MRI in the evaluation of Müllerian duct anomalies. J Clin Imaging 27:346-350

123. Orazi C, Lucchetti C, Schingo PMS, Marchetti P, Ferro F (2007) Herlyn-Werner-Wunderlich syndrome: uterus didelphys, blind hemivagina and ipsilateral renal agenesis. Sonographic and MRI findings in 11 cases. Pediatr Radiol 37:657-665

124. Pui MH (2004) Imaging diagnosis of congenital uterine malformation. Comput Med Imag Graph 28:425-433

125. Brosens JJ, Barker FG, deSouza NM (1998) Myometrial zonal differentiation and uterine junctional zone hyperplasia in the nonpregnant uterus. Hum Reprod Update 4(5):496-502

126. Brosens JJ, de Souza NM, Barker FG (1995) Uterine junctional zone: function and disease. Lancet 346:558-560

127. Fusi L, Cloke B, Brosens JJ (2006) The uterine junctional zone. Best Pract Res Clin Obstet Gynaecol 20(4):479-491

128. Gordts S, Brosens JJ, Fusi L, Benagiano G, Brosens I (2008) Uterine adenomyosis: a need for uniform terminology and consensus classification. RBM Online 17:244-248

129. Minto CL, Hollings N, Hall-Craggs M, Creighton S (2001) Magnetic resonance imaging in the assessment of complex Mullerian anomalies. Br J Obstet Gynecol 108:791-797 
130. Mirkovic L, Ljubic A, Mirkovic D (2006) Magnetic resonance imaging in the evaluation of uterus didelphys with obstructed hemivagina and renal agenesis: a case report. Arch Gynecol Obstet 274:246-247

131. Scarsbrook AF, Moore NR (2003) MRI appearances of Mullerian duct abnormalities. Clin Radiol 58:747-754

132. Takagi H, Matsunami K, Noda K, Furui T, Imai A (2003) Magnetic resonance imaging in the evaluation double uterus and associated urinary tract anomalies: a report of five cases. J Obstet Gynaecol 23:525-527

133. Braun P, Grau FV, Pons RM, Enguix DP (2005) Is hysterosalpingography able to diagnose all uterine malformations correctly? A retrospective study. Eur J Radiol 53:274-279

134. Roma Dalfo A, Ubeda B, Ubeda A, Monzoni M, Rotger R, Ramos R, Palacio A (2004) Diagnostic value of hysterosalpingography in the detection of intrauterine abnormalities: a comparison with hysteroscopy. AJR 183:1405-1409
135. Swart P, Mol BW, van der Veen F, van Beurden M, Redekop WK, Bossuyt PM et al (1995) The accuracy of hysterosalpingography in the diagnosis of tubal pathology: a meta-analysis. Fertil Steril 64:486-491

136. Ott DJ, Fayez JA, Zagoria RJ (eds) (1998) Hysterosalpingography: a text and atlas, 2nd edn. Williams \& Wilkins, Baltimore, MD

137. Renbaum L, Ufberg D, Sammel M, Zhou L, Jabara S, Barnhart K (2002) Reliability of clinicians versus radiologists for detecting abnormalities on hysterosalpingogram films. Fertil Steril 78:614618

138. Philbois O, Guye E, Richard O, Tardieu D, Seffert P, Chavrier Y, Varlet F (2004) Role of laparoscopy in vaginal malformation. An experience in 22 children. Surg Endosc 18:87-91

139. Patterson D, Mueller C, Strubel N, Rivera R, Ginsburg HB, Nadler EP (2006) Laparoscopic neo-os creation in an adolescent with uterus didelphys and obstructed hemivagina. J Pediatr Surg 41:E19-E22 